\title{
Transient Creep Characteristics in Pb-Sn-Zn Ternary Alloys
}

\author{
A. A . El-Daly, A. M. Abdel - Daiem, and M. Yousef \\ Physics Department, Faculty of Science, Zagazig Univ., Zagazig, Egypt
}

Transient creep tests were investigated under different applied stresses ranging from 3.123 to $6.83 \mathrm{MPa}$ for eutectic ( $\mathrm{Pb}-65.5 \mathrm{Sn}-3.4 \mathrm{Zn})$ and $(\mathrm{Pb}-$ $65 \mathrm{Sn}-1 \mathrm{Zn}$ ) ternary alloys. The transient creep is described by $\varepsilon_{t r}=\beta t^{n}$, where $\varepsilon_{t r}$ and $t$ are the transient creep strain and time. Both alloys showed enhancement in the creep parameters $n$ and $\beta$. A small deviation about (20K) of the characteristic point towards lower temperature is obtained in comparison to that of binary eutectic Pb-Sn alloy. DTA analysis indicates low melting temperatures in both alloys. It was concluded that the $\mathrm{Pb}-\mathrm{Sn}-\mathrm{Zn}$ ternary alloys show superior superplastic behaviour compared with the Pb - Sn eutectic composition as a result of the lower melting temperature and the multiplicity of types of interphase boundary causing enhancement in diffusion process. Microstructural analysis support the grain boundary sliding (GBS) as being the mechanism controlling transient creep. 


\section{Introduction}

An extremely wide range of metals and alloys have been reported [1] as exhibiting anomalous ductility or extreme elongations which qualify them to be considered as structurally superplastic. These materials exhibit Superplasticity while undergoing phase transformation. Recently, a study was made of a rate sensitive plastic deformation and superplasticity in alloys of lead and tin [2]

The mechanism by which a metal becomes rate - sensitive, depends on grain size. The important role of composition is its effect on grain growth. The greater the volume of second phase, the lower the rate of grain growth because of the relative immobility of interphase boundaries. Pearson's results [3] on the $\mathrm{Sn}-\mathrm{Pb}$ and $\mathrm{Sn}-\mathrm{Bi}$ eutectics may be interpreted as evidence for grain boundary sliding as the mechanism of deformation. Backofen and Avery [4] proposed the diffusional creep in the principal mode of strain.

However, this phenomenon may be utilized to increase substantially technological ductility and to reduce sharply resistance to deformation i.e., increasing the technical and economic indices of production [5].

In the previous work [6], transient creep tests were carried out on the $\mathrm{Pb}-\mathrm{Sn}$ binary eutectic alloys. Reports of superplasticity in $(\mathrm{Pb}-\mathrm{Sn}-\mathrm{Zn})$ ternary alloys have received little attention from the point of view of the effect of the $\mathrm{Zn}$ content on the transient creep behaviour.

The aim of the present work is to investigate the characteristics and the structural properties of the transient creep in the eutectic $(\mathrm{Pb}-65.5 \mathrm{Sn}-3.4 \mathrm{Zn})$ and $(\mathrm{Pb}-65 \mathrm{Sn}-1 \mathrm{Zn})$ ternary alloys.

\section{Experimental}

$\mathrm{Pb}-65.5 \mathrm{Sn}-3.4 \mathrm{Zn}$ and $\mathrm{Pb}-65 \mathrm{Sn}-1 \mathrm{Zn}$ ternary alloys were prepared from $\mathrm{Pb}, \mathrm{Sn}$, and $\mathrm{Zn}$ (purity $99.99 \%$ ) by vacuum melting. The ingots were rolled into wires. In this study, the wires were annealed at $413 \mathrm{~K}$ for 2 hours and then slowly cooled to room temperature at a cooling rate $\mathrm{T}=2 \times 10-2$ $\mathrm{K} / \mathrm{sec}$. After this heat treatment, the samples were considered to be completely precipitated [7]. Creep deformation were performed on annealed wire samples of $0.8 \mathrm{~mm}$ diameter and $50 \mathrm{~mm}$ gauge length. The slowly cooled samples were crept under constant applied stresses ranging from 3.123 to $6.83 \mathrm{MPa}$ at temperatures ranging from 353 to $413 \mathrm{~K}$ using a conventional type creep machine [8]. The samples were crept also at constant temperature (393K) under different stresses. The accuracy of temperature measurement is of the order \pm $1 \mathrm{~K}$. Strain measurements were done with an accuracy of $\pm 10^{-5} \mathrm{~m}$. 
Differential thermal analysis (DTA) was carried out using DU Pont 990 thermal analyzer (USA). All measurements were carried out in Nitrogen atmosphere .The samples were placed in aluminum crucible. The temperature range was from 393 to $503 \mathrm{~K}$ with heating rate of $10{ }^{\circ} \mathrm{C} / \mathrm{min}$. The transient creep parameters $\beta$ and $n$ were determined by Friadel's equation [9];

$$
\varepsilon_{\mathrm{tr}}=\beta \mathrm{t}^{\mathrm{n}}
$$

The exponent $\mathrm{n}$ was determined from the slope relating $\ln \varepsilon_{\mathrm{tr}}$ and $\ln \mathrm{t}$, while the parameter $\beta$ was calculated from:

$$
\ln \beta=\left(\operatorname{lnt}_{2} \varepsilon_{\mathrm{tr} 1}-\operatorname{lnt}_{1} \varepsilon_{\mathrm{tr} 2}\right) / \operatorname{lnt}_{2}-\operatorname{lnt}_{1}
$$

The parameter $\beta$ was found to depend on the strain rate of the steady state creep $\left(\varepsilon_{\mathrm{st}}\right)$ through the relation [10].

$$
\beta=\beta_{0}\left(\varepsilon_{\mathrm{st}}\right) \gamma
$$

where, $\beta_{0}$ and $\gamma$ are constants depend on the experimental conditions.

\section{Results}

Isothermal creep curves for the present two alloys were studied using different applied stresses at different working temperatures ranging from 353 to $413 \mathrm{~K}$ in steps of $10 \mathrm{~K}$ (see Fig. 1). The sequence of creep curves with respect to the temperature show a pronounced superplastic behaviour especially at high temperatures. Fig. 2 shows the creep behaviour as a plot of $\ln \varepsilon \operatorname{tr}$ against $\ln \mathrm{t}$. The transient creep parameters $n$ and $\beta$ were calculated from Eq. (1). The exponent $\mathrm{n}$ was calculated from the slopes of the lines in Fig. (2) and was found to have values ranging from 0.7 to 1.08 for $\mathrm{Pb}-65.5 \mathrm{Sn}-3.4 \mathrm{Zn}$ alloy, and from 0.66 to 1.07 for $\mathrm{Pb}-65 \mathrm{Sn}-1 \mathrm{Zn}$ alloy. The parameter $\beta$ was calculated from Eq. 2 and was found to exhibit values ranging from $0.6 \times 10^{-4}$ to $19 \times 10^{-4}$ for $\mathrm{Pb}-65.5 \mathrm{Sn}-3.4 \mathrm{Zn}$ alloy and from $2.5 \times 10^{-4}$ to $21 \times 10^{-4}$ for $\mathrm{Pb}-65 \mathrm{Sn}-1 \mathrm{Zn}$ alloy. 

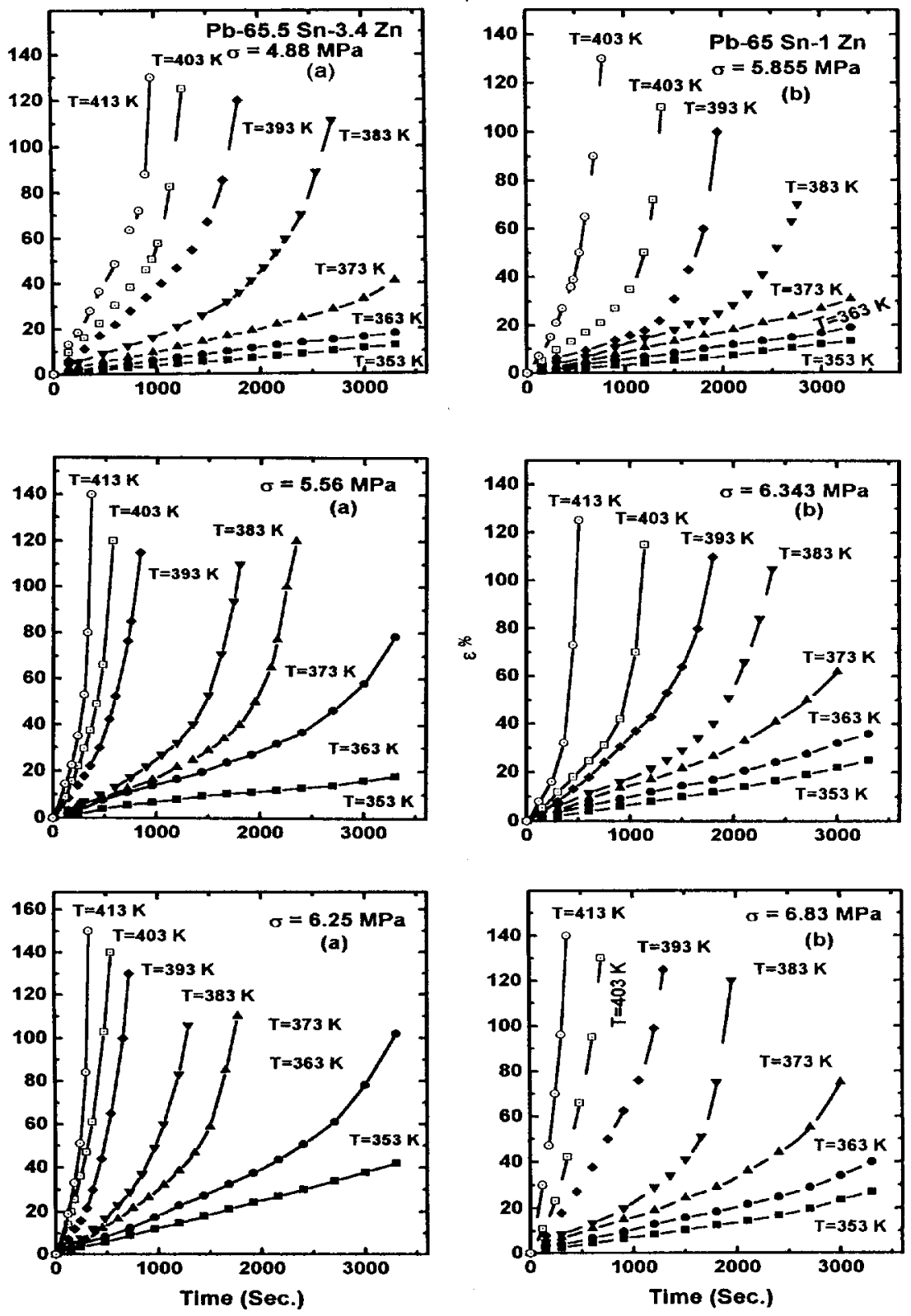

Fig. (1) : Creep Curves at different applied stresses and different temperature for for a) $\mathrm{Pb}-65.5 \mathrm{Sn}-3.4 \mathrm{Zn}$ and $\mathrm{b}) \mathrm{Pb}-65 \mathrm{Sn}-1 \mathrm{Zn}$ ternary alloys. 

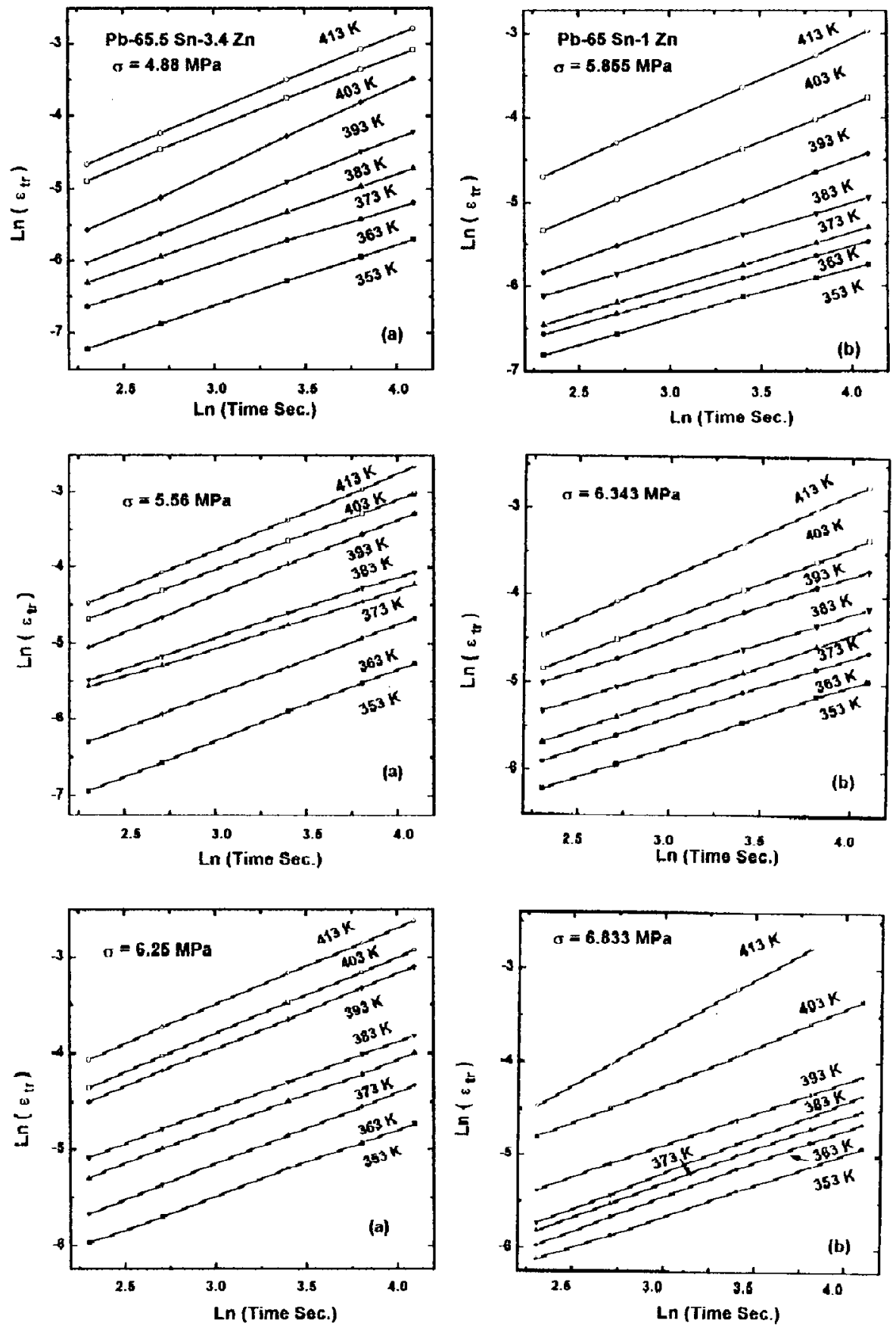

Fig.(2) : Relation between $\ln \left(\varepsilon_{t r}\right)$ and $\operatorname{lnt}$ for: a) $\mathrm{Pb}-65.5 \mathrm{Sn}-3.4 \mathrm{Zn}$ and $\quad$ b) $\mathrm{Pb}-65$ $\mathrm{Sn}-1 \mathrm{Zn}$ ternary alloys at different stresses and various temperatures. 
Fig. 3 represents the temperature dependence of $n$ and $\beta$ for both alloys under the experimental conditions considered above. It can be seen that there are two distinct regions in the tested temperature range suggesting enhanced temperature dependence for $n$ and $\beta$ occur at $383 \mathrm{~K}$. This behaviour occur in the region above $0.5 \mathrm{~T}_{\mathrm{m}}$ and may explain why the creep is enhanced above $0.5 \mathrm{~T}_{\mathrm{m}}$. The mechanical response here seems to depend on the change in the internal structure ordering including the basic rearrangement in the grain boundaries at elevated temperatures and the rate-controlling step. Fig 4 shows the deformation microstructure changes with changing temperature. The main feature of all samples is that : a) the grains have an equiaxed shape, b) some grains are displaced as a whole above or below the original surface and therefore, a lack of focus is observed, c) the grains and phase boundaries become wavy and curved, d) the grains are rotated and its boundaries are distorted.
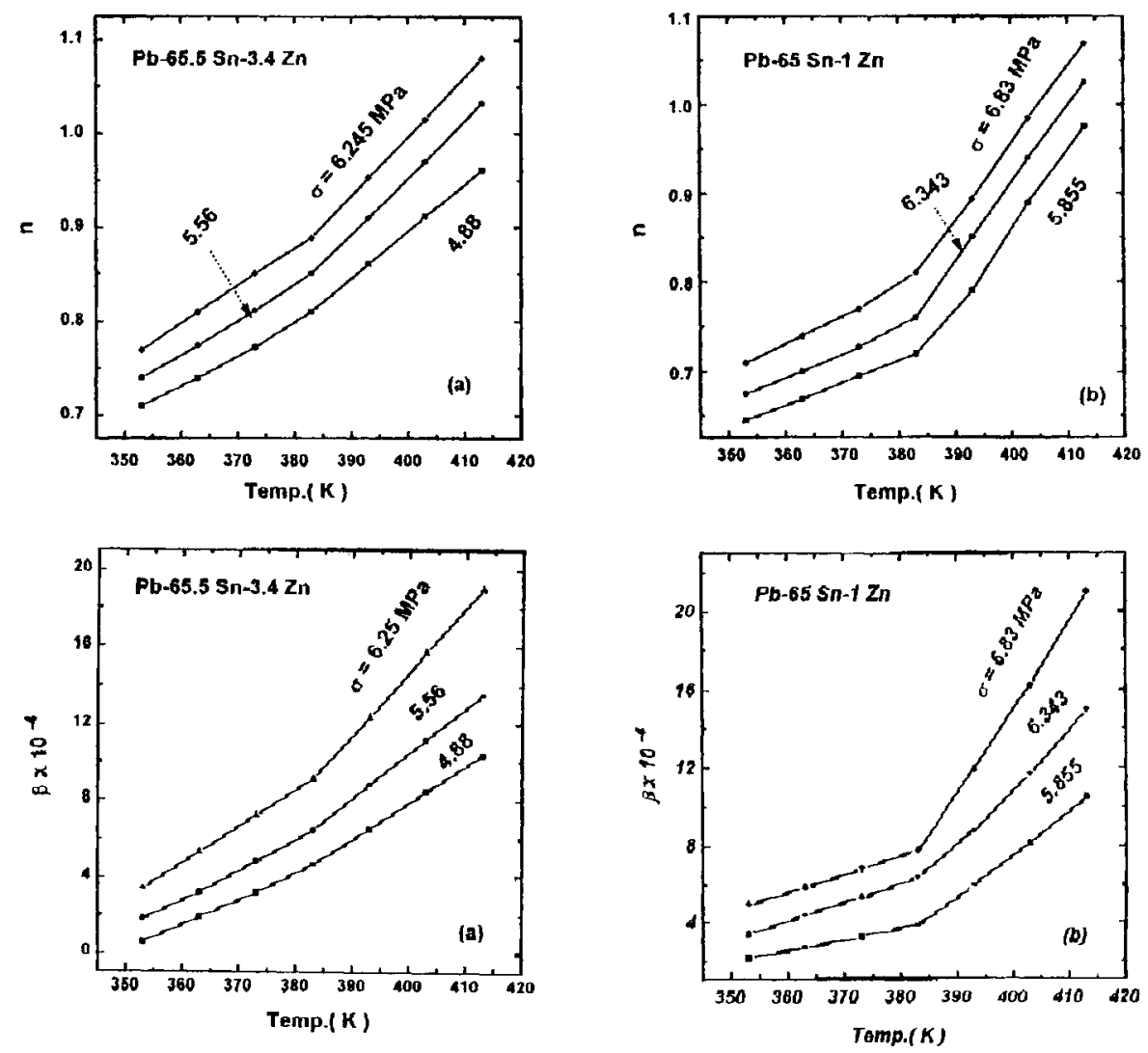

Fig. (3) : The dependence of the parameters $n, \beta$ on the working temperature at different applied stresses for a) $\mathrm{Pb}-65.5 \mathrm{Sn}-3.4 \mathrm{Zn}$ and b) $\mathrm{Pb}-65 \mathrm{Sn}$ $1 \mathrm{Zn}$ ternary alloys. 


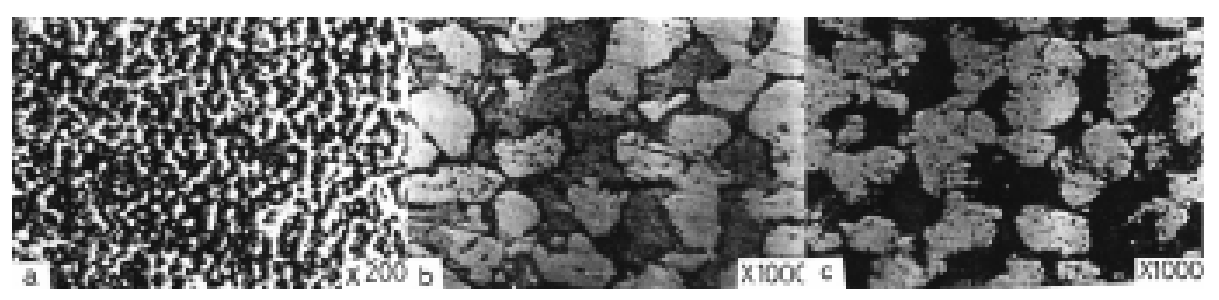

Fig. (4): Grain boundary sliding in Pb-Sn-Zn-ternary eutectic.Note: a) Wavy and curved grains, the displacement of grains as a whole has occurred above or below the original surface at $413 \mathrm{~K}$. b) The boundary are broad and curved at 363 K. c) Distorted boundaries at 403 K. A progressive change with $\mathrm{T}$ is evident.
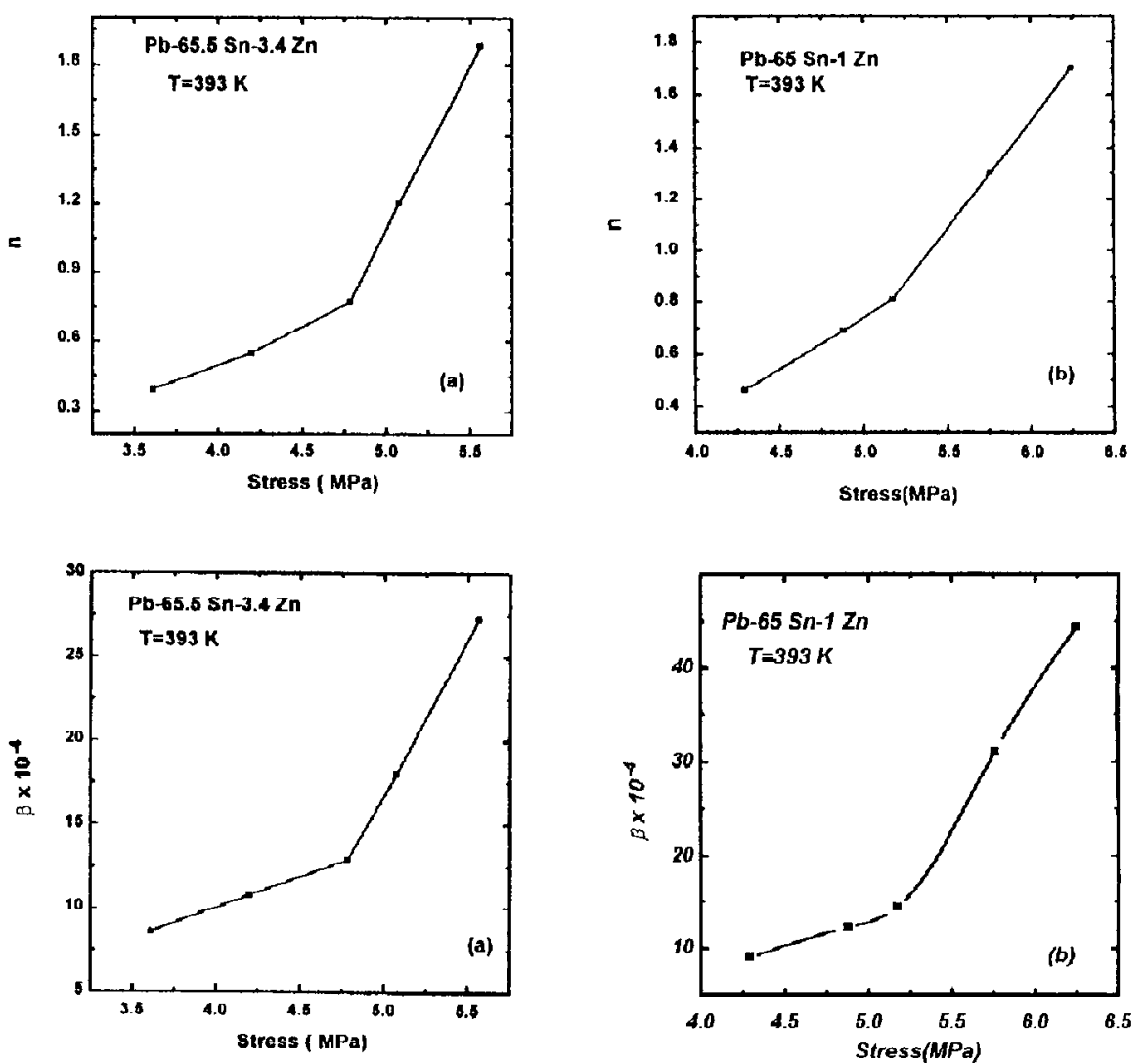

Fig. (5) : The dependence of the parameters $n, \beta$ on the applied stress at constant temperature $393 \mathrm{~K}$ for a) $\mathrm{Pb}-65.5 \mathrm{Sn}-3.4 \mathrm{Zn}$ and b) $\mathrm{Pb}-65 \mathrm{Sn}-1 \mathrm{Zn}$ ternary alloys. 
In performing creep tests at temperature $393 \mathrm{~K}$ under different applied stresses ranging from 3.61 to $5.56 \mathrm{MPa}$ for the eutectic alloy and from 4.29 to 6.245 MPa for the second alloy, it can be seen that the stress dependence of the parametrers $n, \beta$ at constant temperature (see Fig.5) were enhanced at a characteristic stress starting for the eutectic alloy at $\sigma \geq 4.75 \mathrm{MPa}$ while for the second alloy started at $\sigma \geq 5.2 \mathrm{Mpa}$. This means that the ternary eutectic alloy is more superplastic than the second alloy, as long as this enhancement depends on the $\mathrm{Zn}$ content in both alloys.
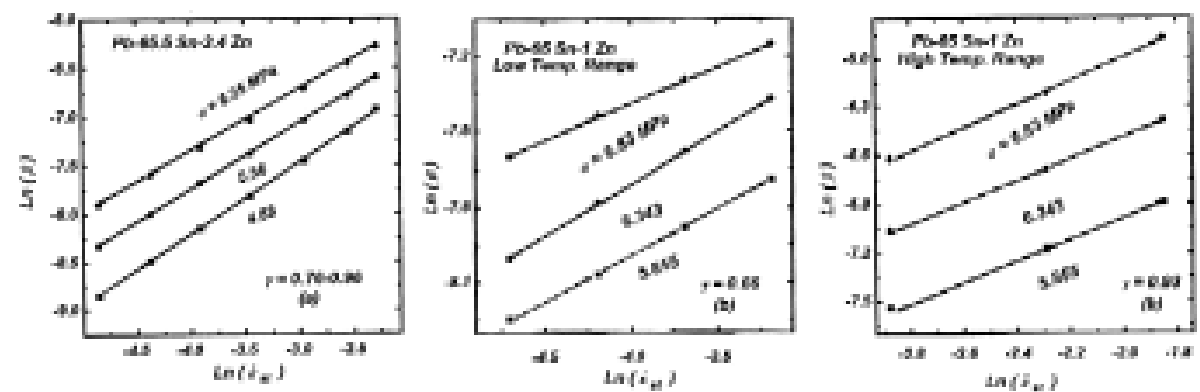

Fig. (6) : The variation of the transient creep parameter $\ln \beta$ with the steady state creep lnest for different applied stresses for a) $\mathrm{Pb}-65.5 \mathrm{Sn}-3.4 \mathrm{Zn}$ and b) $\mathrm{Pb}-65 \mathrm{Sn}-1 \mathrm{Zn}$ ternary alloys

In order to correlate between transient and steady state creep, from Eq. (3), the relation between $\ln \beta$ and $\ln \varepsilon s t$, for different constant stresses, was plotted, (see Fig. 6). Eq. (3) was found to be valid with the exponent $\gamma$ ranging from 0.76 to 0.96 and from 0.66 to 0.93 for $\mathrm{Pb}-65.5 \mathrm{Sn}-3.4 \mathrm{Zn}$, and $\mathrm{Pb}-65 \mathrm{Sn}-$ $1 \mathrm{Zn}$ alloys, respectively. The activation enthalpy of the transient creep $\mathrm{Q}_{\mathrm{tr}}$ was calculated using the following equation [6]:

$$
\varepsilon_{\mathrm{tr}}=\varepsilon_{0}+\mathrm{t}^{\mathrm{n}} \exp \left(\frac{-\mathrm{Q}_{t r}}{k T}\right)
$$

where $\varepsilon_{0}$ is the instantaneous strain.

Fig. 7 illustrates the relation between $\ln \varepsilon_{\text {tr }}$ and 1000/T. These results yield activation enthalpies of 20.53 and $55 \mathrm{KJ} / \mathrm{mole}$ for $\mathrm{Pb}-65.5 \mathrm{Sn}-3.4 \mathrm{Zn}$, and 22.66 and $58.23 \mathrm{KJ} /$ mole for $\mathrm{Pb}-65 \mathrm{Sn}-1 \mathrm{Zn}$ alloy, in low and high temperature regions, respectively.

An experimental correlation was found between the residual internal strain and the variation of the precise values of lattice parameters is illustrated (see Fig. 8) for both $\mathrm{Pb}, \mathrm{Zn}$, and Sn-rich phases. The lattice parameter $\mathrm{a}_{0}$ reached 

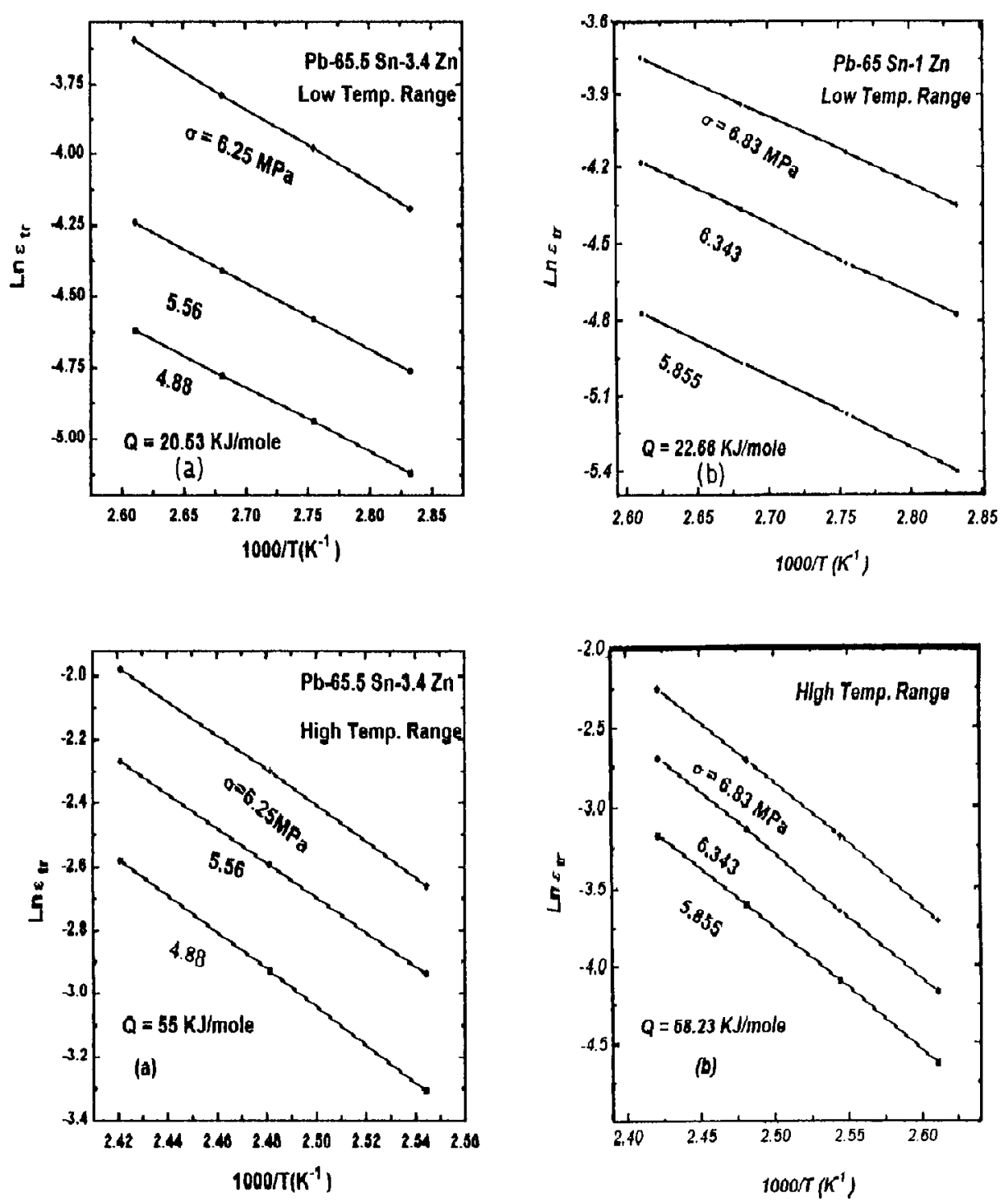

Fig. (7) : The relation between $\operatorname{Ln}\left(\varepsilon_{\mathrm{tr}}\right)$ and 1000/T for different applied stresses for a) $\mathrm{Pb}-65.5 \mathrm{Sn}-3.4 \mathrm{Zn}$ and $\mathrm{b}) \mathrm{Pb}-65 \mathrm{Sn}-1 \mathrm{Zn}$ ternary alloys.

maximum for $\mathrm{Pb}$ - rich phases, while the ratio $\left(\delta_{\mathrm{o}} / \mathrm{a}_{\mathrm{o}}\right)$ reached minimum for $\mathrm{Sn}$, and Zn-rich phases. Fig. 9 shows the results of DTA examination of two specimens. The thermoanalytical curves have endothermal peaks at $447.9 \mathrm{~K}$ and $455 \mathrm{~K}$ for $\mathrm{Pb}-65.5 \mathrm{Sn}-3.4 \mathrm{Zn}$ and $\mathrm{Pb}-65 \mathrm{Sn}-1 \mathrm{Zn}$ ternary alloys, respectively. The peak temperatures correspond to the melting temperature, $\mathrm{T}_{\mathrm{m}}$, for two alloys. 


\section{Discussion}

In the present study the nature of transient creep is found to be markedly dependent on the microstructural changes and the working temperature as well as
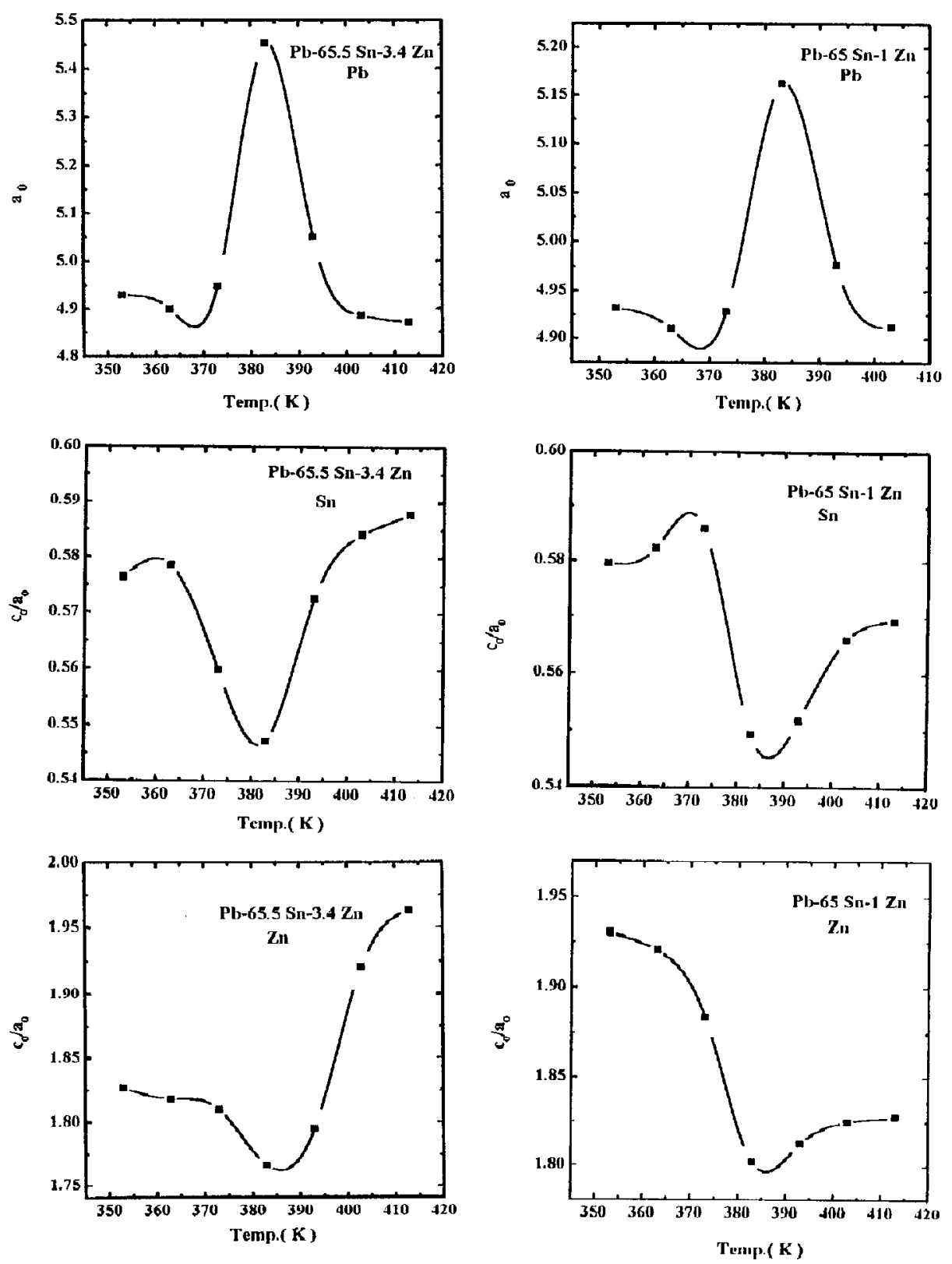

Fig. (8) : The effect of creep temperature on the precise lattice parameter $\mathrm{a}_{\mathrm{o}} \mathrm{Pb}$-rich Phase and the rates $\left(\delta_{0} / a_{0}\right)$ of Sn and and Zn-rich phases. 


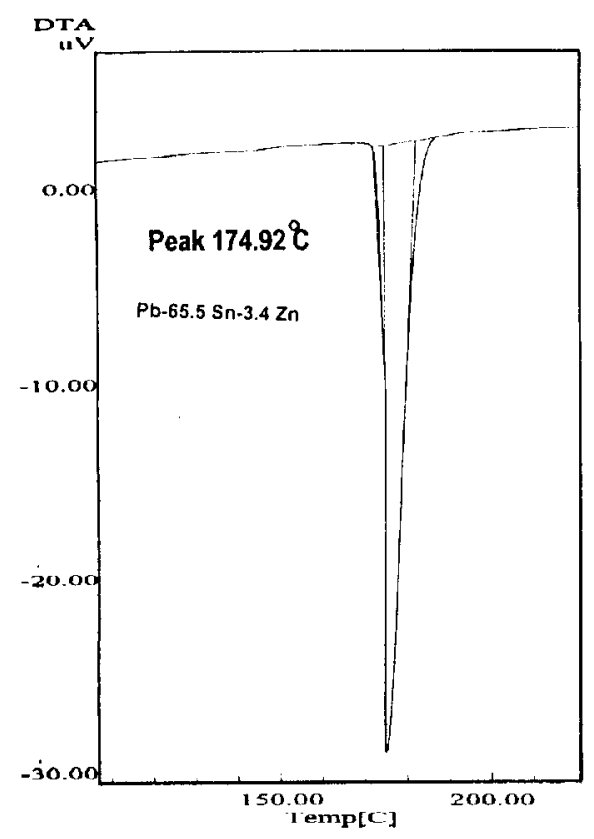

(a)

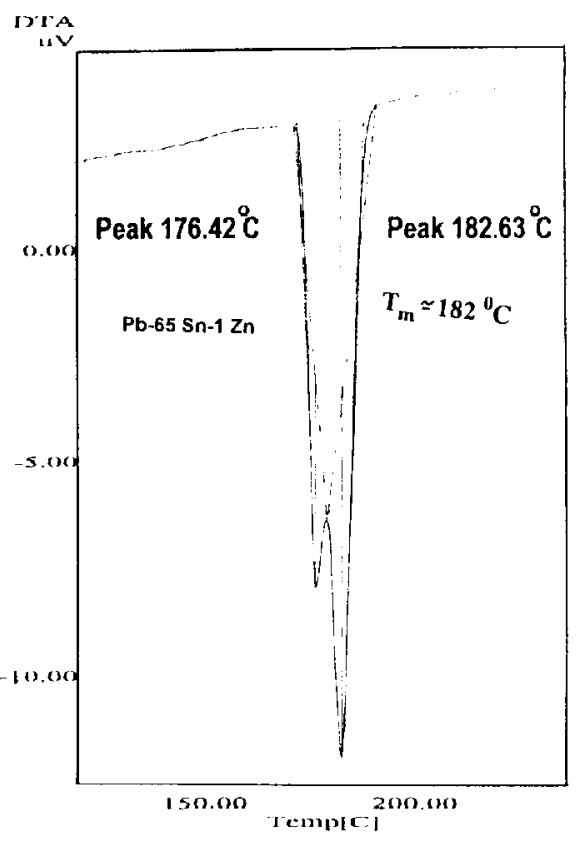

(b)

Fig. (9) : Differential thermal analysis (DTA) for a) Pb-65.5 Sn-3.4 Zn and b) Pb-65 Sn- $\mathrm{Zn}$ ternary alloys in the temperature range from 403 to $673 \mathrm{~K}$

the applied stresses. The temperature dependence of the calculated values of $n$ and $\beta$ of the two compositions show a characteristic temperature at $383 \mathrm{~K}$. In a previous work [6], a similar behaviour at $403 \mathrm{~K}$ for binary eutectic $\mathrm{Pb}-\mathrm{Sn}$ alloy has been observed. The discrepancy between these obtained temperatures might be attributed to the effect of a third phase ( $\mathrm{Zn}$ - rich phase) in $\mathrm{Pb}-\mathrm{Sn}-\mathrm{Zn}$ alloys [11]. The enhanced creep of the two alloys above $383 \mathrm{~K}$ as observed from the variation of the parameters $n$ and $\beta$ below and above this temperature might be attributed to the increased mutual solubility of the constituent phases above $383 \mathrm{~K}$. The observed increase in $\mathrm{n}$ and $\beta$, could be ascribed to the variations in the microstructure of the three phases due to the changes in their quantitative proportions [11].

The most likely mechanism proposed to explain this phenomenon was suggested by Bochvar [12]. On the basis of this model, two conditions were necessary to observe superplasticity. These are rapid variations in composition with temperature and high rate of diffusion at the deformation temperature. The first condition leads to a solution process at some of the interfaces and to a precipitation process at the others. This change in the distribution of the composition entities implies diffusion currents and movement direction of 
atoms leading to viscous deformation or superplasticity. The second condition implies increasing interface area and decreasing diffusion lengths, which enhance superplasticity. In this context, the increased number of phases leads to an increased number of different types of interphase boundaries. For example, in $\mathrm{Pb}-\mathrm{Sn}-\mathrm{Zn}$ ternary alloys there will be $\mathrm{Pb} / \mathrm{Sn}, \mathrm{Pb} / \mathrm{Zn}, \mathrm{Pb} / \mathrm{Pb}, \mathrm{Sn} / \mathrm{Sn}, \mathrm{Zn} / \mathrm{Zn}$, and $\mathrm{Sn} / \mathrm{Zn}$ phase boundaries [13], while in $\mathrm{Pb}-\mathrm{Sn}$ binary alloys there will be three phase boundaries only. Therefore, it is expected that the $\mathrm{Pb}-\mathrm{Sn}$ base ternary alloys show enhanced superplastic properties higher than those of the binary $\mathrm{Pb}$ - Sn alloys as indicated by the enhanced values of creep parameters summarized in Table 1.

Table (1): Comparison of the transient creep characteristics of Pb-Sn $\mathrm{Zn}$ ternary alloys with $\mathbf{P b}$ - Sn binary eutectic alloy.

\begin{tabular}{|c|c|c|c|c|c|c|}
\hline Materials & exponent $\gamma$ & Exponent $\mathrm{n}$ & $\begin{array}{c}\text { Parameter } \\
\beta\left(10^{-4}\right)\end{array}$ & $\begin{array}{c}\text { Activation } \\
\text { Energy } \\
\mathrm{Q}(\mathrm{KJ} / \mathrm{mol})\end{array}$ & $\begin{array}{c}\text { Melting } \\
\text { Temp. Tm }\end{array}$ & Reference \\
\hline $\begin{array}{r}\mathrm{Pb}-\mathrm{Sn} \\
\text { eutectic }\end{array}$ & $0.7-0.85$ & $0.63-0.96$ & $0.3-4.0$ & $25-63$ & $456 \mathrm{~K}[11]$ & {$[6]$} \\
\hline $\begin{array}{c}\mathrm{Pb}-\mathrm{Sn}-3.4 \\
\mathrm{Zn} \text { eutectic }\end{array}$ & $0.76-0.96$ & $0.7-1.08$ & $0.6-19.0$ & $20.53-55.0$ & $447.9 \mathrm{~K}$ & $\begin{array}{c}\text { Present } \\
\text { work }\end{array}$ \\
\hline $\begin{array}{c}\mathrm{Pb}-\mathrm{Sn}- \\
1 \mathrm{Zn} \text { alloy }\end{array}$ & $0.66-0.93$ & $0.66-1.05$ & $2.5-21.0$ & $22.7-58.23$ & $455 \mathrm{~K}$ & $\begin{array}{c}\text { Present } \\
\text { work }\end{array}$ \\
\hline
\end{tabular}

Table (1) presents a comparative format of some important characteristics of transient creep in binary eutectic $\mathrm{Pb}$ - $\mathrm{Sn}$ alloy and ternary $\mathrm{Pb}$ $\mathrm{Sn}-\mathrm{Zn}$ alloys. On the basis of these data, it is clear that diffusion is also reinforced by the addition of $\mathrm{Zn}$ which enhances the diffusivity in $\mathrm{Pb}-\mathrm{Sn}-\mathrm{Zn}$ alloys and gives rise to superior superplastic properties.

The isothermal tests at constant temperature in the present work clearly indicate the stress dependence of the transient creep parameters (Fig.5) .It is clear that the greater the $\mathrm{Zn}$ content in the alloy, the smaller is the stress required to enhance the creep parameters. Therefore, $\mathrm{Zn}$ particles principally seem to refine and stabilize equiaxed grains of tin and lead -rich solid solutions [14]. This might be attributed to its inhibiting effect on grain growth [13]. 
The enhancement of transient creep parameters by increasing the applied stress might be attributed to the superposition of the applied stress on the internal stresses set up during rearrangements caused by the difference in specific volumes $\Delta \mathrm{v} / \mathrm{v}$ of the existing phases [10]. According to these statements, the excess strain associated with these variations might be of a magnitude as greet as $\Delta \mathrm{v} / \mathrm{v}$. In ternary alloys we expect that $\Delta \mathrm{v} / \mathrm{v}$ is higher than in binary $\mathrm{Pb}-\mathrm{Sn}$ eutectic. This expectation seems to be acceptable as $\Delta \mathrm{v} / \mathrm{v}$ is directly dependent on the difference in strength expressed as the shear modulus of the constituent phases concerned [15]. It was found that [16] the shear modulus of $\mathrm{Zn}>\mathrm{Sn}>\mathrm{Pb}$ is as the ratio $5.75: 2: 1$, respectively. Therefore, the enhanced creep parameters might be caused by the large difference in the strengths between the constituent phases.

In order to correlate transient and steady state creep, the linear relation between $\ln \beta$ and $\ln \varepsilon s t$ for different constant stresses through phase transformation, was plotted (see Fig.6). The relation $\beta=\beta_{0}\left(\varepsilon_{\mathrm{st}}\right)^{\gamma}$ connecting $\beta$ and $\varepsilon_{\text {st }}$ was found to be valid. The values of the exponent $\gamma$ obtained from Fig.6 as $0.76-0.96$ and $0.66-0.93$ for the two alloys, respectively, seem to be effectively induced by the presence of $\mathrm{Zn}$ - rich phase which enhances the transient and steady state creep stages. The creep deformation is based on the mechanical properties of the constituent phases [17]. On the basis of this statement, the difference in the strengths between the constituent phases can cause simultaneous change in the internal stress. Subsequently, this leads to a change in the kinetics of dislocation motion at the phase boundaries, giving rise to grain boundary sliding [18]. The activation enthalpies (see Fig.7) indicate that the transient creep of $\mathrm{Pb}-\mathrm{Sn}-\mathrm{Zn}$ alloys in the low temperature region might be controlled by dislocation intersection [6], while at high temperatures, creep might be controlled by grain boundary sliding [13].

From the results of DTA, Tm for ternary $\mathrm{Pb}-\mathrm{Sn}-\mathrm{Zn}$ alloys is lower than that of binary alloys (see Table 1). It is clear therefore that, as $\mathrm{Zn}$ content increases the melting temperature decreases. The fact that the lower the eutectic temperature for the alloy the better the superplastic properties [19], strongly suggests that the enhanced superplastic behaviour observed in our ternary alloys might be related to its lower melting temperature. The microstructure study in Fig.( 8 ) is direct evidence for the characteristic change in the creep parameters at $383 \mathrm{~K}$. On the other hand, the evidence of the internal grain deformation is more direct to indicate that GBS is the deformation mechanism 
dominating in the high temperature region (see Fig 4). The equiaxed grains, the displacement of the grains above or below the original surface, the curved and wavy grains and the distorted boundaries are well documented clue that GBS which can be detected from the intensity variations in the micrographs of Fig.4 plays an essential role controlling creep behaviour $[13,14]$.

\section{Conclusion}

1. In the present study ternary $\mathrm{Pb}-\mathrm{Sn}-\mathrm{Zn}$ alloys show superior superplastic behavior compared to previous work on $\mathrm{Pb}$ - $\mathrm{Sn}$ binary alloys as a result of two important factors, namely; the low melting temperature and the multiplicity of types of interphase boundary.

2. The presence of third phases ( $\mathrm{Zn}$ content) in $\mathrm{Pb}-\mathrm{Sn}-\mathrm{Zn}$ ternary alloy seems to play a significant role responsible for these two factors.

3. The transient creep parameters $\mathrm{n}$ and $\beta$ have a strong temperature dependence exemplified by an activation energy of $20.53,55.0 \mathrm{KJ} / \mathrm{mol}$ and 22.66-58.23KJ/mol for $\mathrm{Pb}-65.5 \mathrm{Sn}-3.4 \mathrm{Zn}$ and $\mathrm{Pb}-65 \mathrm{Sn}-1 \mathrm{Zn}$ alloys respectively, in the low and high temperature regions, confirming dislocation intersection and grain boundary sliding controlling mechanisms.

\section{Reference}

1. K. A. Padmanabhan and G. J. Davies; "Superplasticity mechanical and structural aspects", Berlin Heidelberg New York, P. 44,74 (1980).

2. H. E. Cline and T. H. Alden; Trans MIME, 239, 711 (1967).

3. C.E. Pearson; J. Inst. Metals 54, 111 (1934).

4. D.H. Avery and W.A. Backoffen; Trans. Mm. Soc. Metals 58, 551 (1965).

5. A.A. Presnyakovi "Superplasticity of metals and alloys" England, p.136, (1976).

6. A. Z. Mohamed, M.S. Saker, A. M. Abdel - Daiem, and M. Shehab; phys. stat. sol. (a) 133, 51 (1992).

7. M. S. Saker, A. Z. Mohamed, A. A. El - Daly, A. M. Abdel - Daiem, and A. H. Bassyouni; Egypt. J. Solids B2, 34 (1990). 
8. R. Kamel and F. Bessa; J. Appl. Phys. 34, 1883 (1963).

9. J. Friedel; Dislocation, Pergamon press, London 1964 (p. 304).

10. M. S. Saker, A. E. E. Abdel - Raaheim, and A. A. El - Daly Phys. Stat.Sol.(a) 89,157 (1985)

11. M. Hansen and K. Anderko; "Constitution of binary alloys" McGraw-Hill Publ. Co, New York 1958, (p.1217).

12. P. Chavdhari; Acta. Metall. 15, 1777 (1967).

13. M. D. C. Moles and G. J. Davies; Metal Science, 314 September (1976).

14. T. H. Alden; Acta Metall 15, 469, (1967).

15. F. W. Clinard and O.D. Sherbyi; Acta Metall, 12, 911 (1964).

16. O. D. Sherby and J. Weertman; Acta Metall. 27, 387 (1979)

17. M. R. Nagy, M. S. Saker, and R. Kamel; Indian J. phys. .55A, 179 (1981).

18. C. N. Ahlquist and W. D. Nix; Acta. Metall. 19,373 (1971).

19. E.E.Underwood, J.Metla 14, 914 (1962). 